\title{
ARTICLE
}

\section{Development of Mobile Radiation Detection System against Nuclear Terrorism in Korea}

\author{
Sung-Woo KWAK*, Sung-Soon CHANG, and Ho-Sik YOO \\ Korea Institute of Nuclear Non-proliferation and Control \\ Expo-Ro 573, Yuseong, Daejeon, 305-732 Korea
}

\begin{abstract}
A fixed radiation portal monitors (RPM) deployed at border, seaport, airport or key traffic checkpoints has played an important role in preventing the illicit trafficking and transport of nuclear and radioactive materials. However, the RPM usually is large and heavy and can't easily be moved to a different location. An intelligent terrorist may also circumvent the fixed RPM to avoid being detected. These reasons motivate us to develop a mobile radiation detection system. The objective of this paper is to report our experience on developing the mobile radiation detection system for the search and detection of nuclear and radioactive materials during road transport. Measurements were performed at various speeds and distances between the radioactive isotope(RI) transporting car and the measurement car. Results of our measurements and the detection limits of the system is described in this paper. The mobile radiation detection system developed should contribute to defending public's health and safety and the environment against nuclear and radiological terrorism by detecting nuclear or radioactive material hidden illegally in a vehicle.
\end{abstract}

\section{KEYWORDS: mobile radiation detection system, nuclear terrorism, illicit trafficking and transport, gamma-ray detector, neutron detector}

\section{Introduction}

Recent events - the 9/11 terrorist attacks, the discovery of Al-Qaeda's experimentation to build a dirty bomb and the death of a former officer of the Russian Federal Security Service from Po-210-induced acute radiation exposure show that the threats relating to nuclear and radioactive materials is no more incredible but serious and credible. There is an urgent need to adopt appropriate and effective measures in order to prevent, detect and respond to such threats. In this regard, increasingly large number of fixed radiation portal monitors (RPMs) have been deployed to prevent and detect nuclear and radioactive materials from being smuggled into one's own country and to ensure that such materials don't fall into the hands of terrorist groups or criminal organizations. However, the RPM usually is large and heavy and can't easily be moved to a different location. An intelligent nuclear or radiological terrorist may also circumvent the fixed RPM to avoid being detected. In other hand, secrecy screening at a roadside would increase effectiveness of inspection of any suspect container or vehicle. These are because a detection system easy to move from place to place and complementary to the RPM - a mobile radiation detection system - is required.

Over the past few years, there have been some reports on a system for the search and detection of nuclear and radioactive materials during a road transport[4-6]. Performance of the system reported in the previous study was dependent on the characteristics of a radiation detector and background noise reduction technique that they adopted.

We have developed a mobile radiation detection system consisting of some radiation detectors (two He-3 gas detectors for neutron detection, two plastic scintillation

*Corresponding Author, Tel:+82-42-860-9783;

Fax:+82-42-861-8819; E-mail:swkwak@kinac.re.kr

(C) Atomic Energy Society of Japan detectors and one $\mathrm{NaI}(\mathrm{Tl})$ for gamma ray detection), a data acquisition system, a GPS(Global Positioning System), a mobile unit(SUV) and an operation software. Field test using various radioactive sources(Ba-133, Cs-137, Co-60, Cf-252) was conducted to characterize performance of the developed mobile radiation detection system.

This mobile radiation detection system is complementary to a fixed RPM. Its application would not only achieve defense-in-depth concept suggested by international recommendations but also improve the ability to detect illicit trafficking and transport of nuclear and radioactive materials[1,2]. Thus, deployment of this inconspicuous and mobile detection system should contribute to protect the people's safety and health and the environment from nuclear and radiological terrorism.

\section{System Construction}

Instruments for detecting and characterizing nuclear and radioactive materials at port of entry (border, seaport, airport etc) or inside countries can be divided into four types : fixed radiation portal monitors (RPMs), personal radiation detectors(PRDs), hand held radionuclide identification devices(RIDs), and hand held neutron search detectors(NSDs)[3]. In addition to these equipment, there is another useful detection system, that is, a mobile radiation detection. The mobile radiation detection system makes it possible to inspect confidentially a suspicious vehicle at random places because of its easy mobility from place to place. Also, the more distant the detection position is from the targeted building/area, the longer time the response force in charge of responding to such nuclear/radiological terrorism can be given for establishing appropriate and effective measures. Thus, this mobile radiation detection system can make contribution to enhancing the national ability to prevent and detect the illicit trafficking and 
transport of nuclear and radioactive materials.

The mobile radiation detection system consists of some radiation detectors (one $\mathrm{NaI}(\mathrm{Tl})$, two $30 \mathrm{~cm} \times 30 \mathrm{~cm} \times 5.7 \mathrm{~cm}$ BC412 plastic scintillation detectors, and two He-3 neutron detectors), a GPS (Global Positioning System), a data acquisition system(DAS), an operation software, and a mobile unit(SUV). Figure 1 shows the developed mobile radiation detection system. In Figure 1, a $7.62 \mathrm{~cm}(3$ inch) diameter x $7.62 \mathrm{~cm}(3 \mathrm{inch})$ length $\mathrm{NaI}(\mathrm{Tl})$ for identification of radionuclide while the plastic scintillator for deciding whether any targeted material is present in a suspect vehicle. A $3.81 \mathrm{~cm}(1.5$ inch) PMT is mounted on a $30 \mathrm{~cm} \times 5.7 \mathrm{~cm}$ edges to collect signal generated in the plastic scintillator. Except of one $30 \mathrm{~cm} \times 30 \mathrm{~cm}$ face of the plastic scintillation detector which radiation is incident on, the other sides are shielded with metal plates of $\mathrm{Fe}, \mathrm{Pb}$ and $\mathrm{Al}$ to increase SNR(Signal-to-Noise Ration) through reduction of background radiation. Two He-3 neutron detectors are in a vehicle as shown in Figure 1. Its dimension and gas pressure are $7.62 \mathrm{~cm}(3 \mathrm{inch})$ diameter $\times 22.86 \mathrm{~cm}(9$ inch) length and 4 atm, respectively. It is surrounded with $5 \mathrm{~cm}$ polyethylene(P.E.) container to improve its sensitivity by slowing down incident neutron. The optimal thickness of $5 \mathrm{~cm}$ P.E was determined using MCNP simulation and verified by experiment using bare Cf-252. The gamma ray detectors can be placed not only on the roof of a mobile vehicle but also inside a vehicle. A pan and tilt machine is used to adjust direction of incident surface of the gamma detectors when it is on vehicle's roof.

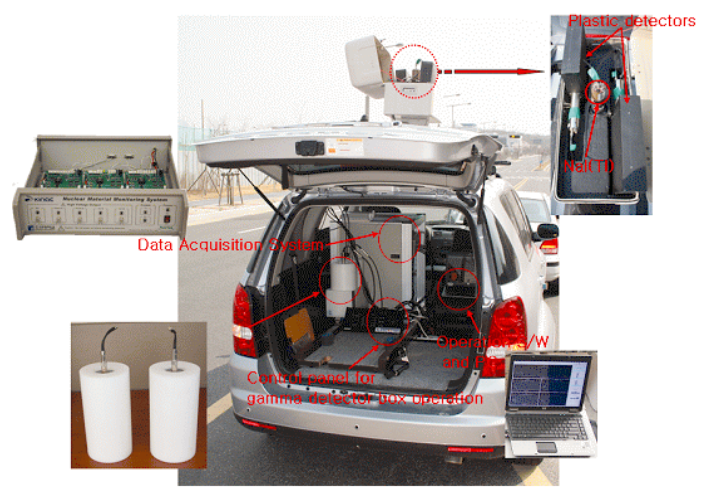

Fig. 1 The developed mobile radiation detection system consisting of some radiation detectors, a GPS, a DAS, an operation software, and a mobile unit

\section{Performance Test}

An experiment to characterize our system's ability to detect nuclear and radioactive materials hidden in a car was made at various speed and at various distances between the RI source transporting car and the measurement car(mobile radiation detection system). As shown Figure 2, the mobile radiation detection system was parked at a roadside and another car transporting a radioactive source moved along three traffic lanes(traffic lane 1, 2, and 3 in Figure 2). Each traffic lane in a road has a width of $3.5 \mathrm{~m}$. The sources used in experiment are about $50 \mu \mathrm{Ci} \mathrm{Ba}-133,50 \mu \mathrm{Ci} \mathrm{Cs}-137,20$ $\mu \mathrm{Ci}$ Co-60, and $4.4 \mu \mathrm{Ci}$ Cf-252.

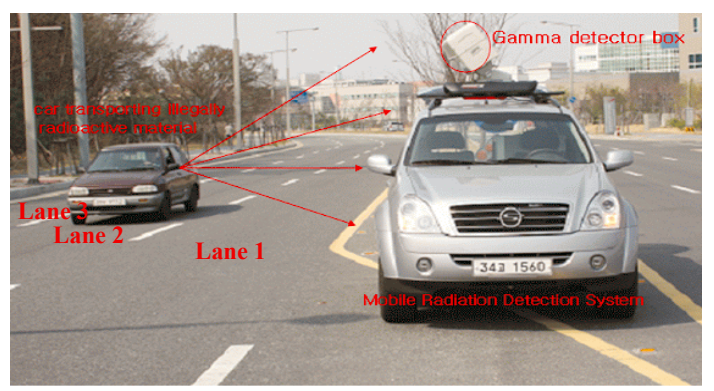

Fig. 2 Field test to characterize performance of the developed mobile radiation detection system

Figure 3 was obtained when the $20 \mu \mathrm{Ci}$ Co-60 transporting car moved at the speed of $20 \mathrm{~km} / \mathrm{hr}$ and 80 $\mathrm{km} / \mathrm{hr}$ in traffic lane 1 . Count rate of the plastic detector in Figure 3 is a sum of count rates of two plastic detectors. In Figure 3, the X-axis is distance between the RI source(Co-60) transporting car and the measurement car; The minus distance in the $\mathrm{x}$-axis means that the source transporting car is approaching the measurement car from behind; The zero is the very moment when the source transporting car passes by the measurement car. For $20 \mathrm{~km} / \mathrm{hr}$, radiation count rates of both $\mathrm{NaI}(\mathrm{Tl})$ and plastic detectors are obviously distinguishable from ambient background radiation. In contrast to $20 \mathrm{~km} / \mathrm{hr}$, signals at $80 \mathrm{~km} / \mathrm{hr}$ speed are relatively small even though those can be distinguished from background. Figure 4 is the result obtained when the RI transporting car moved along traffic lane 3 as shown in Figure 2. The radiation signal of $80 \mathrm{~km} / \mathrm{hr}$ was not distinguishable from background radiation. Figure 4 shows that our detection system can detect about up to $20 \mu \mathrm{Ci}$ Co-60 when it is transported at the speed of $60 \mathrm{~km} / \mathrm{hr}$ in traffic lane 3. The ability to detect Ba-133, Cs-137, and Cf-252 was also determined in the same way. From the measurement results, it appeared that detection limits of our system for Ba-133, Cs-137, and Cf-252 were speed of 30 $\mathrm{km} / \mathrm{hr}$ in traffic lane $1,30 \mathrm{~km} / \mathrm{hr}$ in traffic lane 2 , and 60 $\mathrm{km} / \mathrm{hr}$ in traffic lane 2 , respectively.

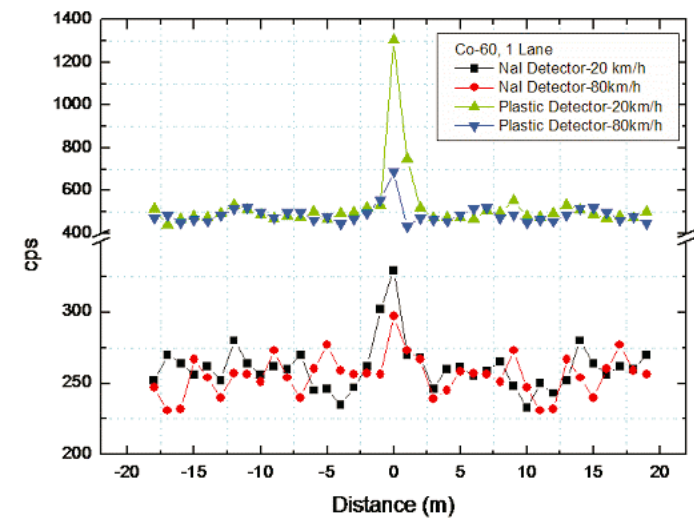

Fig. 3 Detection signal when the Co-60 transporting car moved with speed of $20 \mathrm{~km} / \mathrm{hr}$ and $80 \mathrm{~km} / \mathrm{hr}$ along traffic lane 1 


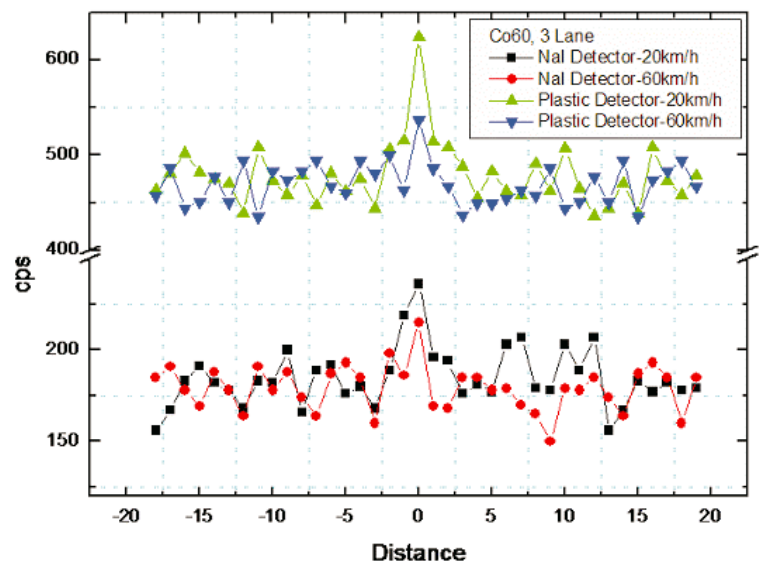

Fig. 4 Detection signal when the Co-60 transporting car moved with speed of $20 \mathrm{~km} / \mathrm{hr}$ and $60 \mathrm{~km} / \mathrm{hr}$ along traffic lane 3

Information from radiation detectors is displayed in operation software. The operation software provides real-time location information, radiation (gamma-ray and neutron) count rate, a emergency contact point of competent authorities responsible for response measure and procedure. Under normal condition, the main window of the operation software as shown in Figure 5 exhibits location information of the detection car on the left and radiation count rate in blue on the right. But when detection radiation signal is higher than a given threshold, an alarm window appears automatically as an overlap on the map. A radiation indication in main and alarm windows changes from blue to red. An audible alarm also sounds. An operator of the mobile radiation detection system can identify the unknown radioactive material using energy spectrum obtained with $\mathrm{NaI}(\mathrm{Tl})$ and plastic detectors.

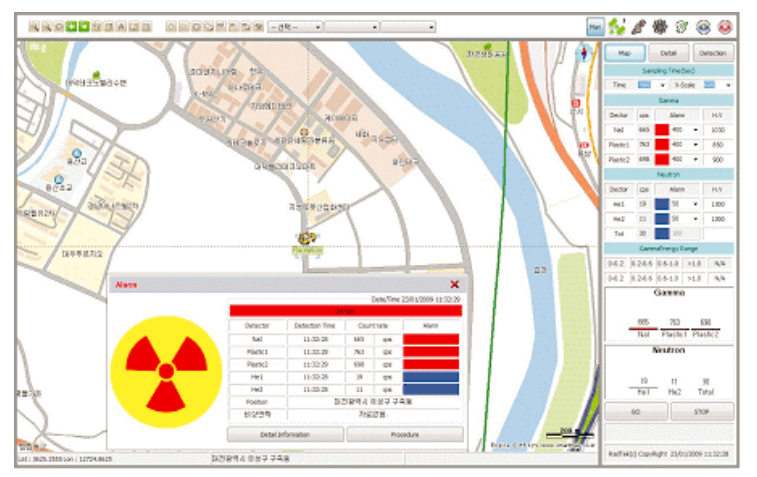

Fig. 5 Alarm window appearing when nuclear or radioactive material is detected

\section{Conclusion and Discussion}

A mobile radiation detection system has been designed, assembled and tested. The detection sensitivity of the system depends on several factors such as the characteristics of radiation detector, the speed that the source is moving, the distance between the source transporting car and the measurement car, and the ambient background radiation. The test results showed that detection limits of our system for 50 $\mu \mathrm{Ci} \mathrm{Ba}-133,50 \mu \mathrm{Ci} \mathrm{Cs}-137,20 \mu \mathrm{Ci} \mathrm{Co}-60$, and $4.4 \mu \mathrm{Ci}$ Cf-252 were speed of $30 \mathrm{~km} / \mathrm{hr}$ in traffic lane $1,30 \mathrm{~km} / \mathrm{hr}$ in traffic lane $2,60 \mathrm{~km} / \mathrm{hr}$ in traffic lane 3 , and $60 \mathrm{~km} / \mathrm{hr}$ in traffic lane 2 , respectively.

Randy Jones et al. reported that the mobile $\mathrm{RN}$ sensor system could detect and identify $70 \mu \mathrm{Ci} \mathrm{Cs}-137$ at up to $112.63 \mathrm{~km} / \mathrm{hr}(70 \mathrm{mph})[5]$. Upp D.L. et al. concluded that their system could be used at $16.09 \mathrm{~km} / \mathrm{hr}(10 \mathrm{mph})$ to $32.18 \mathrm{~km} / \mathrm{hr}(20 \mathrm{mph})$ for the best results and the useful distances for sources in the $10 \mathrm{~s}$ of $\mu \mathrm{Ci}$ is $12 \mathrm{~m}$ or less[6]. The neutron signal has similar sensitivities. Also, it is reported that one commercial product can detect $10 \mu \mathrm{Ci}$ Cs-137 in a distance of $3 \mathrm{~m}, 17 \mu \mathrm{Ci}$ Co-60 in a distance of $6 \mathrm{~m}$, and $36 \mu \mathrm{Ci} \mathrm{Cf}-252$ in the distance of $5 \mathrm{~m}$ when these sources move at the speed of $16.09 \mathrm{~km} / \mathrm{hr}$ [7]. Compared with performance of the existing system, it is concluded that performance of our system is comparable to those of the existing system.

The mobile detection system described in this paper could be deployed to prevent and detect illicit trafficking and transport of nuclear and radioactive materials. However, there are something to be improved. The first is the ability to identify a radionuclide in very short time. The second is to make the operation software simple for end-user to use easily it.

\section{References}

1) IAEA INFCIRC/225/Rev.4, The Physical Protection of Nuclear Material and Nuclear Facilities, International Atomic Energy Agency, Vienna(1999).

2) GICNT, Model Guidelines Document for Nuclear Detection Architectures, draft(2008).

3) International Atomic Energy Agency, Technical and Functional Specifications for Border Monitoring Equipment, IAEA Nuclear Security Series No.1, IAEA, Vienna(2006).

4) T. Köble, W. Rosenstock, M. Risse, J. Peter, "Detection of Nuclear Material During Fast Road Transport," Proc. INMM 44, Annual Meeting, 2003, USA(2003).

5) Randy Jones, Rollin Evans, Gary Smith, "A Mobile Radiation Detection System for the Sensitive Detection and Identification of Radiological/Nuclear Threats," Proc. INMM 45, Annual Meeting, 2004, USA(2004).

6) Upp, D.L., Keyser, R.M., "Performance of a Car-mounted Neutron and Gamma-ray Monitoring System for Illicit Material Detection," Proc. INMM 45, Annual Meeting, 2004, USA(2004).

7) Radiation Detection System V2.5 NaI-SS, www.ortec-online.com. 